\title{
Genética, biologia molecular e ética: as relações trabalho e saúde*
}

\author{
Genetics, molecular biology and ethics: \\ work and health connections
}

Gilka Jorge Figaro Gattás 1

$M$ arco Segre 1

Victor Wünsch Filho 2

* Este trabalho foi conduzido dentro do escopo de suporte financeiro da USP/Fapesp/FM USP.

1 Departamento de M edicina Legal, Ética M édica e M edicina Social e do Trabalho. Faculdade de M edicina, Universidade de São Paulo. Rua Teodoro Sampaio, 115 05405-000 São Paulo SP.

gfgattas@usp.br 2 Departamento de Epidemiologia, Faculdade de Saúde Pública, Universidade de São Paulo. wunsch@usp.br
Abstract This paper provides a discussion about the increasing development of genetics and molecular biomarkers technologies and consequent impact on practices of occupational health. Genetic analysis could be in specific populations at occupational, pharmacological or environmental exposures. Current knowledge of human genome open up the possibility of individual genetic screening of disease susceptibility among those exposed in workplaces to chemical or physical hazards, or for late onset hereditary disease. Epidemiological studies including genetic and molecular biology approaches have been designed to evaluate the interaction of genetically determined metabolic variants with different environmental exposures on the risk of diseases. The strategy for worker's health promotion must be maintained on the surveillance of hazardous exposure risks in occupational settings and not in worker's genetic screening. Ethical behavior in occupational health can vary from country to country and even between occupational health practitioners and researchers. To discuss the need for a social responsibility context in the use of genetic information in which ethical actions in occupational health could be conducted is the main purpose of this paper.

Key words Molecular genetics, Workers health, Ethics, Genetic screening, Genetic epidemiology
Resumo 0 artigo discute 0 impacto dos avanços da genética e da biologia molecular sobre a prática em saúde ocupacional. 0 conhecimento atual sobre o genoma humano permite, em certas circunstâncias, identificar fatores individuais de susceti bilidade a doenças em si tuações de exposição a substâncias químicas ou físicas, ou ainda, a doenças genéticas de manifestação tardia. Estudos epidemiológi cos incorporando elementos da genética e da biologia molecular têm sido desenhados para avaliar a interação de variantes metabólicas e exposições ambientais no risco de ocorrência de diferentes doenças. A pesar desta perspectiva, consi dera-se que as pesqui sas nesta área são ainda incipientes. A estratégia para a redução dos danos causados à saúde do trabalhador deve continuar a ter como base, prioritariamente, a modificação e a adequação dos ambientes de trabalho e não a especificação genética da força de trabal ho. Introduzir a discussão sobre a necessidade de definir princípios de responsabilidade social no uso de informações genéticas e que possam reger ações éticas em saúde do trabalhador éuma das propostas principais deste artigo.

Palavras-chave Genética molecular, Saúde do trabalhador, Ética, Rastreamento genético, Epidemiologia genética 


\section{Introdução}

De acordo com a legislação trabalhista, empregadores podem selecionar seus empregados com base no grau de instrução e na experiência profissional anterior, mas não podem usar como critério de seleção condições específicas como idade, sexo, cor de pele e origem étnica. A tualmente, informações sobre o perfil genético de candidatos a emprego têm sido incluídas em processos seletivos. N os Estados Unidos, estudos recentes estimaram que cerca de $7 \%$ das empresas americanas já fazem uso do screening genético na sel eção de seus trabal hadores (Austin et al., 2000). 0 número de informações genéticas tende a aumentar constantemente e, entre as numerosas razões apontadas para o uso destas informações como critério para seleção de trabalhadores, destaca-se a possibilidade de identificar indivíduos suscetíveis de virem a apresentar determinadas doenças como decorrência da interação entre a especificidade de um genótipo particular e a exposição a substâncias tóxicas presentes no ambiente de trabalho.

A discriminação genética no trabalho, apesar das novas tecnologias da biologia molecular, não é um fato novo. Na década de 1970, bem antes do início do Projeto Genoma Humano, os negros americanos que possuíam traços genéticos para anemia falciforme eram impedidos de contratação em determinadas ocupações, embora apresentassem condições adequadas de saúde e ausência de riscos de virem a desenvolver a doença (Rothenberg et al., 1997). A primeira legislação proibindo esse tipo de intervenção segregacionista ocorreu na Carolina do N orte, em 1975, estendendo-se posteriormente para os demais estados americanos.

A biologia molecular tem fornecido as ferramentas básicas para geneticistas e epidemiologistas aprofundarem-se nos mecanismos moleculares que influem na variação da distribuição de doenças nas famílias e nas populações. A divulgação da seqüência do genoma humano em fevereiro de 2001 (Venter et al., 2001) abriu uma nova era para a biologia, a medicina e a saúde pública. O Projeto Genoma Humano gerou uma imensa base de dados de seqüências genômicas e número crescente de genes é descrito. A tualizações permanentes estão disponíveis no endereço eletrônico do $\mathrm{Na}$ tional Center for Biotechnology Information (NCBI) dos Estados Unidos (www.ncbi.nIm. nih.gov). A velocidade com que esse conhecimento vem sendo disseminado traz, ao lado da esperança de cura para certas doenças, 0 receio das conseqüências adversas que possam vir a sofrer indivíduos saudáveis, porém portadores de determinadas alterações genéticas (Ellsworth \& M anolio, 1997).

As informações e as tecnologias disponibilizadas com o desenvolvimento do Projeto Genoma H umano têm potencial para modificar gradativamente a compreensão e os conceitos atuais sobre os mecanismos de prevenção, diagnóstico e tratamento de inúmeras doenças crônicas bastante comuns como câncer, demência, doença de Alzheimer, $M$ al de H untington, diabetes mellitus, hipertensão arterial e doença coronariana, asma e outras alergias, bem como outras doenças com expressão epidemiológica em saúde pública. Por meio de técnicas de biologia molecular é possível não apenas identificar precocemente determinadas doenças, mas também detectar indivíduos suscetíveis e, ainda, avaliar no meio interno do organismo o grau de exposição a agentes exógenos (Wünsch Filho \& Gattás, 2001). Fatores ambientais, tanto os ligados ao estilo de vida quanto os decorrentes de exposições nos locais de trabal ho ou no ambiente geral, têm influência distinta sobre os indivíduos com relação ao risco de determinadas doenças. As diferenças interindividuais parecem estar associadas à capacidade de ligação de substâncias exógenas ao DNA e à variabilidade na capacidade de reparo dos danos causados no material biológico das células, e também à herança genética, fatos que, isoladamente ou em conjunto, aumentariam o risco individual para a ocorrência de doenças na dependência de interação com fatores ambientais (Khoury, 1998; Taningher et al., 1999).

Considerando-se que grande parte da exposição a agentes tóxicos ocorre em ambientes ocupacionais, muitos estudos têm sido realizados nas últimas décadas nos países desenvolvidos com o objetivo de identificar indivíduos portadores de genes responsáveis pela maior ou menor susceptibilidade a esses agentes. I sto deverá modificar e ampliar substancialmente 0 espectro de ações a serem aplicadas na saúde ocupacional. $N$ as próximas décadas, a identificação de danos não perceptíveis (diagnóstico preditivo), com possíveis efeitos num futuro mais distante sobre a qualidade de vida dos indivíduos, será objeto privilegiado de interesse em saúde do trabalhador. 
Também deverá se tornar tema central de pesquisas, e conseqüentemente de preocupação para a intervenção pelos serviços de saúde, a compreensão dos mecanismos de interação entre genes e exposições ambientais e seus efeitos na reprodução, com potencial interferência na saúde da progênie dos trabal hadores expostos.

$N$ ão apenas em pesquisas, mas também no acompanhamento clínico, visando ao diagnóstico precoce de indivíduos com potencial suscetibilidade genética em populações específicas expostas a situações de risco, o uso de técnicas de biologia molecular envolve a coleta e o armazenamento de amostras biológicas, a análise e a interpretação dos resultados obtidos. Então, a discussão dos potenciais riscos destes procedimentos, tanto para o indivíduo como para a comunidade, é sempre fonte de preocupações e conflitos éticos (Ellsworth \& M anolio, 1997; H oltzman \& Andrews, 1997; Wicks et al., 1999).

0 objetivo deste artigo é discutir aspectos relacionados à evolução da genética e da biologia molecular, procurando identificar as influências deste novo conhecimento para a pesquisa epidemiológica das relações trabal hosaúde e para as ações em saúde do trabalhador; examinar as inter-relações e interfaces destes campos e as implicações éticas deste processo.

\section{A plicações e limites da genética e da biologia molecular}

O campo da genética molecular expande-se muito rapidamente para al ém da abrangência tradicional da genética médica, como a identificação de erros inatos do metabolismo e de defeitos congênitos (Khoury et al., 1993). Deve-se considerar, entretanto, que muito ainda deverá ser estudado antes de se obter o mapeamento e a seqüência completa de genes relacionados a diferentes doenças. $M$ as, sem dúvida, os dados acumulados pelo Projeto Genoma H umano, com um sistema integrado de informações, deverá influenciar gradativamente a prática da medicina e da saúde pública no decorrer do século 21, modificando de forma profunda a prevenção, o diagnóstico e o tratamento de doenças (Collins, 1999). Há estudos apontando genes que seriam potencialmente responsáveis, por exemplo, pelo al coolismo, tabagismo e distúrbios comportamentais (Plotsky \& N emerof, 1998; Bergen \& Caporaso,
1999; Collins \& M ckusick, 2001). Estetipo de informação genética, potencialmente, apresenta riscos de usos inadequados nos locais de trabalho e por companhias seguradoras. Os efeitos de tudo isso sobre a práxis em saúde do trabalhador são evidentes, embora não possam ainda ser completamente dimensionados.

\section{Exposições ambientais e biomarcadores moleculares}

Os avanços da genética molecular ampliaram o espectro das abordagens epidemiológicas e novos sub-ramos foram propostos e desenvolvidos, como a epidemiologia genética (Khoury et al., 1993; Khoury, 1998) e a epidemiologia molecular (H ulka et al., 1990; Schulte \& Perera, 1993). Essas abordagens permitiram uma melhor compreensão da interação entre fatores ambientais e genéticos na causalidade de doenças, aspecto central na epidemiologia moderna (W ünsch Filho, 2000).

Em geral, as avaliações de exposições nos locais de trabal ho têm sido conduzidas pela mensuração de substâncias químicas ou agentes físicos presentes num determinado ambiente confinado. A pesar das inúmeras críticas sobre os limites destes procedimentos analíticos, este tipo de avaliação tem sido a rotina empregada pela área de higiene industrial, que pouco mudou suas práticas nas últimas décadas (Armstrong et al., 1992). Entretanto, é crescente, por exemplo, o número de processos produtivos que são considerados cancerígenos, ou seja, atividades nas quais se observa excesso de câncer entre os trabalhadores que as exercem (IARC, 1987; 1999a; 1999b; 1999c). N estas situações, o trabalhador está exposto a um perfil de misturas complexas de químicos com potencial deletério sobre a sua saúde (Vainio et al., 1990). Este fato é particularmente verdadeiro na indústria da borracha. A ausência de estudos epidemiológicos com detalhes sobre diferentes exposições dificulta estabelecer a associação entre substâncias químicas específicas utilizadas no processo industrial da borracha e local izações particulares de câncer. A razão fundamental desta deficiência é a considerável quantidade de aditivos químicos (várias centenas) utilizados neste processo produtivo. Além disso, a necessidade de altas pressões e temperaturas na fase de vulcanização produz muitas outras substâncias químicas desconhecidas que são continuamente liberadas no ambiente. Esta condição de exposição 
complexa apresenta diferenças entre fábricas, tipo de produção e controle tecnológico, e variações na prática de trabalho.

Os contínuos avanços da biologia molecular têm potencial para auxiliar na distinção de substâncias presentes nos ambientes de trabaIho e caracterizar exposições específicas ( $\mathrm{Pe}$ rera \& Dickey, 1997). Se a composição química de uma mistura complexa é bem caracterizada e detalhada do ponto de vista toxicológico e epidemiológico, então indicadores de exposição específicos de dose externa, interna e biologi camente efetiva, podem ser obtidos. Em particular, na avaliação das doses biológicas efetivas os biomarcadores moleculares podem ser úteis. Entretanto, a seleção de um biomarcador apropriado como índice de exposição a determinado cancerígeno é bastante difícil. As concentrações de substâncias nas misturas complexas variam nos ambientes de trabalho e no tempo. U ma estratégia para identificar as frações atribuíveis a componentes específicos na mistura seria utilizar uma avaliação por etapas (Perera et al., 1990; Vermeulen, 2001). Inicialmente, a exposição ambiental é caracterizada da forma mais completa possível. I sto provê uma estimativa do padrão de exposição para a mistura química e, se possível, para seus constituintes individuais. Esta etapa tem sido o limite convencional da higiene industrial. A segunda etapa seria analisar a relação entre exposição ambiental e biomarcadores de exposição de relevância. A identificação e a quantificação de efeitos genotóxicos precoces no meio interno dos indivíduos desdobram-se desde biomarcadores inespecíficos (aberrações cromossômicas, trocas de cromátides irmãs, mutações gênicas, ativação de oncogenes) a biomarcadores específicos de exposição a um tipo de classe química (por exemplo, adutos de hidrocarbononetos policíclicos aromáticos-DNA), e, posteriormente, biomarcadores de exposição a um químico específico (por exemplo, adutos de benzopireno-DNA). N esta última etapa, identificam-se as contribuições da biologia molecular que poderão ser incluídas nos procedimentos de rotina de avaliação ambiental num futuro próximo.

Os estudos epidemiológi cos com marcadores moleculares, como os adutos de DNA no pulmão e as aberrações cromossômicas nos linfócitos, podem sugerir um risco potencial precoce. Entretanto, deve-se ressaltar que a mensuração direta deste potencial mutagênico por meio destes biomarcadores nunca de- tectou um cancerígeno importante e, mesmo atualmente, não pode prover estimativas de risco confiáveis (Peto, 2001).

\section{Suscetibilidade individual e biomarcadores moleculares}

As exposições ocupacionais podem atuar como agentes silenciosos na indução de danos no DNA. Os estudos desenvolvidos para a compreensão da carcinogênese constituem-se nos mais avançados model os construídos para a compreensão das relações entre exposi ções ambientais e suscetibilidade individual. O câncer é atualmente considerado uma doença genética que se manifesta pelo acúmulo de mutações no DNA no decorrer de um espaço de tempo quase sempre longo ( para uma revisão de biomarcadores em câncer ver referência Wünsch Filho \& Gattás, 2001). 0 acúmulo de alterações no material genético da célula depende de vários fatores endógenos como sexo, idade e constituição genética, e exógenos como hábitos de consumo, alimentação, uso de medicamentos, exposição a químicos, etc. A análise da combinação destes fatores endógenos e exógenos pela epidemiologia visa inferir o risco individual de um trabalhador vir a desenvolver câncer, frente a uma determinada ocu pação. Existe grande variabilidade, de indivíduo para indivíduo, quanto à capacidade de bi otransformação e eliminação de substâncias químicas estranhas ao organismo também denominadas xenobióticos.

Dois tipos principais de enzimas estão envolvidas no metabolismo de xenobióticos: as enzimas da família do citocromo P450 (enzimas da fase I de metabolização), responsáveis por reações de oxi dação de substâncias exógenas em compostos el etrofílicos, e enzimas da fase II, as quais atuam geralmente como enzimas de inativação de compostos e incluem as da família da glutationa-S-transferase (GSTs) e N-acetil-transferase (NATs) (Parkinson, 1996). Essas enzimas, geneticamente determinadas, regulam a intensidade e duração dos efeitos de xenobióticos no organismo e desempenham papel principal na toxicidade e carcinogenicidade de substâncias químicas. Associações entre determinados genótipos destas enzimas e incidência de neoplasias vêm sendo descritas na literatura (Caporaso et al., 1992; Smith et al., 1995; Raunio et al., 1995).

A pós extração do DNA, a identificação dos diferentes genótipos enzimáticos é possível 
através da técnica de reação em cadeia da polimerase (PCR - polymerase chain reaction), seguida de tratamento com enzimas de restrição específicas. Os genótipos são classificados de acordo com a presença ou ausência do gene em estudo (null genotype) ou de sítios de restrição específicos os quais permitem revelar mutações na seqüência gênica (Figura 1 ).

Portanto, de forma análoga, por meio de técnicas relativamente simples de biologia molecular é possível caracterizar o genótipo de um indivíduo quanto a determinados genes de suscetibilidade, logo após o nascimento e antes de quaisquer exposições ou manifestações clínicas de distintas doen ças. Estes testes possibilitam monitorar o trabalhador exposto, promovendo uma ação primária de prevenção, mas também permitem classificar in divíduos "mais ou menos" resistentes à determinada exposição. A pesar dos evidentes aspectos benéficos, este conhecimento apresenta potencial para gerar discriminação genética. A utilização desta informação na prática da medicina do trabal ho suscita questionamentos ainda sem resposta, mas que necessitam discussões urgentes pela comunidade científica e sociedade civil: é lícito realizar o screening genético para estas enzimas, visando a uma maior proteção no futuro para os indivíduos portadores de genes desfavoráveis? Como poderá ser usada esta informação quando a ocupação exercida, ou a ser exercida, representar um risco potencial ou iminente? Qual tipo de ocupação será selecionada para um trabal hador que apresentar constituição genética "favorável" à exposição? Poderão esses testes constar entre os solicitados no exame pré-admissional? Poderão esses resultados constituir a "identidade genética" de indivíduos e impedir ou mesmo prejudicar contratações? Serão os homens no futuro prisioneiros da genética?

\section{Considerações éticas no uso de marcadores genéticos}

O Projeto Genoma Humano inovou neste tipo de pesquisa básica e destinou 3-5\% dos recursos para pesquisas sobre aspectos éticos, legais e sociais decorrentes da manipulação de material genético. 0 grupo ELSI (Ethical, Legal, and Social Issues Research), integrante do corpo do projeto, e composto por cientistas sociais, advogados, teólogos, entre outros, foi criado com o objetivo de promover discussões

\section{Figura 1}

Representação dos produtos de amplificação por PCR do gene da família da glutationa-S-transferase (GSTM 1) e da $\beta$-globina (268 pb) queserviu de controle positivo da reação.

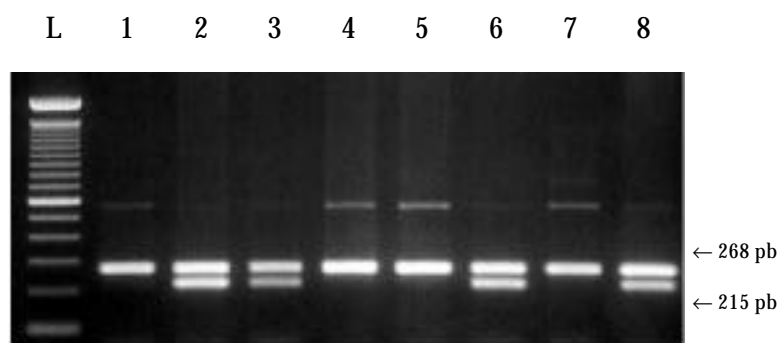

A identificação do genótipo nulo (ausência do gene GSTM 1) é feita em gel de agarose ( $2 \%$ ) corado com brometo de etídeo. Os indivíduos nas colunas 2, 3, 6 e 8 são classificados como GSTM 1 positivos por apresentarem um fragmento de DNA de $215 \mathrm{pb}$. Os demais são classificados como genótipo nulo por não apresentarem a fração de DN A correspondente (Gattás \& Soares-Vieira, 2000).

e estabelecer orientações sobre os dilemas advindos com a melhor compreensão do genoma, principalmente os relacionados à segregação e ao determinismo genético (http:// www.orln.gov/hqmis/elsi/elsi.html).

A pesquisa de marcadores genéticos promove o reconhecimento de el ementos de extrema importância para a prevenção de doenças, mas é um assunto que requer reflexão no âmbito legal, ético e social, com amplo leque de responsabilidades, para impedir que seu uso, de forma não orientada, possa vir a acarretar danos profundos na sociedade. De fato, a identificação de conflitos éticos, ou seja, a não observância dos princípios básicos de beneficência, respeito e justiça ao indivíduo, nem sempre é fácil de ser definida e delimitada, e requer 0 envolvimento no debate de ampla gama de setores da sociedade (Goodman $\&$ Prineas, 1996).

\section{Conhecimento genético e discriminação}

Todo avanço científico traz expectativas, esperanças e, também, medo. Assim foi com a descoberta da fissão nuclear e a criação de uma nova fonte de energia capaz de produzir progresso na qualidade de vida, mas podendo também ser utilizada destrutivamente, aniquilando povos com bombas ou pela poluição radioativa, inviabilizando a vida na Terra. Assim é, já no plano dos costumes, quando se aperfeiçoam os métodos de reprodução assistida, dan- 
do a possibilidade a casai s inférteis de terem prole, mas se teme a desestruturação da família tradicional e "a invasão pelo homem de um setor considerado privativo de Deus". Na verdade, o que assusta são as formas de utilização dos novos conhecimentos e das novas técnicas, e não as descobertas em si. Não parece razoável que se possa reprovar a descoberta da energia nuclear, embora seja cabível, mormente face aos desastres nucleares já ocorridos, temerem-se as conseqüências de sua utilização imprópria ou sem as devidas cautelas.

Todos esses temores são freqüentemente exagerados e infundados, pois desconsideram que a subjugação, a discriminação, o genocídio, e todas as formas de injustiça existem e prosperam desde sempre, mesmo sem qualquer impulso científico. Ademais, toda postura inquisitorial, obstaculizando o desenvolvimento técnico-científico, só produz estagnação sem qualquer avanço moral. 0 processo de mudanças da moralidade está condicionado ao necessário ajuste, contínuo, dos valores tradicionais às novas situações que se apresentam como decorrência do desenvolvimento da humanidade.

Em tempos em que se realiza, com aceleração constante, o seqüenciamento do DNA, em que se vão descobrindo os el ementos genéticos que influem na qualidade de vida, e, ainda mais, quando já se vislumbra a intervenção do homem no gene, alterando suas próprias características e mesmo de gerações futuras, é compreensível que se temam as conseqüências desse progresso, e que se afirme, com certo pavor: $0 \mathrm{H}$ omem não pode querer brincar de Deus! (Como se esse procedimento lúdico não tivesse sempre acompanhado a evolução da espécie, incluindo-se aí a descoberta de medicamentos que extinguiram doenças e al ongaram a vida... o que também poderia ser considerado um atentado contra os desígnios divinos!).

É perfeitamente compreensível que haja esperanças e receios decorrentes da conclusão do Projeto Genoma Humano. A ciência progride descortinando os determinantes da vida, particularmente na presciência de doenças, e interfere assim no comportamento e nas escolhas a serem feitas. Com base nessas premissas, talvez, erroneamente, pudesse ser depreendido que o homem é tão somente o resultado de um projeto de informática transcendental.

Ainda que se tragam as especificidades da biologia molecular para dentro de seus limites, isto é, não atribuindo ao DN A o papel de determinante que às vezes se Ihe confere, resta considerar que se trata de um conjunto de informações extremamente importante para a previsão de múltiplas situações vinculadas à saúde. Assim, suscitam-se variados dilemas éticos inerentes tão apenas ao fato de se empreender um estudo desse tipo em voluntários, ou referentes à utilização por terceiros (agentes de seguros, serviços de saúde ocupacional, o próprio estado) dos dados obtidos.

Toda pesquisa de marcadores genéticos a partir de amostras biológicas de voluntários deve caminhar necessariamente em parceria com eles. $N$ ão se restringe essa partici pação ao consentimento informado, mas também à comunicação a cada sujeito, durante a condução da pesquisa, de tudo o que estiver sendo observado, tendo ele o direito a qualquer momento de pedir a suspensão de sua participação. Será, portanto, extremamente importante a essa altura que a informação seja precisa, consentânea com o mais atualizado pensamento científico, sem minimizar nem superdimensionar a possível influência que o achado de um marcador genético específico poderá ter. Q uanto à adesão não há por que hesitar, nesses casos, ao princípio da autonomia. U m voluntário, devidamente informado quanto ao alcance que a detecção de determinadas alterações poderá ter sobre sua vida e de seus descendentes, tendo uma opção plena de participação no projeto, assumirá conseqüentemente o ônus de administrar as tensões que esse conhecimento Ihe propiciará. Não tem grande peso, neste instante, o registro do fato de que o estudo de seus marcadores genéticos Ihe dará al gumas condições de atenuar, na medida do possível, os aspectos del etérios de seu genoma. Trata-se apenas de assumir, ou não, conscientemente, algum papel na administração de seu futuro. Há que se levantar, nesta ocasião, a possibilidade de um voluntário disporse a participar de uma pesquisa, e, ele mesmo, passar a recusar as informações referentes aos achados que forem sendo feitos. Poderá um pesquisador aceitar o prosseguimento do estudo, estando ele impedido, nessa situação, de indicar medidas para a prevenção ou atenuação de algum futuro malefício que possa advir da herança genética detectada naquele indivíduo?

As questões assim postuladas sequer consideram um outro aspecto importante, as repercussões da informação da bagagem gené- 
tica individual dentro das famílias. No estudo das características genéticas está implícito que as mesmas são herdadas e, em conseqüência, os genes sadios, potencialmente defeituosos ou certamente mutados, se encontram dispersos dentro daquela família modificando de forma substancial o valor de um resultado individual. Como se sentiriam irmãos e demais familiares de um jovem que tivesse sido rejeitado no emprego por apresentar genes desfavoráveis quanto ao risco de exposição a substâncias químicas?

\section{Marcadores genéticos e saúde do trabalhador}

0 seqüenciamento do genoma humano torna-se gradativamente um elo importante entre indivíduos e instituições. As relações entre indivíduos e empregadores, escolas, seguros de saúde, são todas potencialmente influenciadas e modificadas pelo conhecimento do DNA. A genética hoje, além de cuidar do patrimônio genético e da conservação das espécies, emprega tecnologias que permitem identificar mutações no DNA responsáveis pela formação de produtos gênicos não eficazes. É possível, desta forma, identificar não só fatores individuais de suscetibilidade como também doenças genéticas monogênicas ou multifatoriais de manifestação tardia. 0 screening genético de doenças monogênicas, como Huntington e Alzheimer, com sérias repercussões potenciais na saúde do indivíduo e na sua performance no trabalho, não garante a manifestação da doença no futuro, pois depende também da expressividade e penetrância do gene identificado. Assim sendo, portadores de genes mutados podem nunca vir a apresentar doença. Trabalhadores geneticamente suscetíveis podem nunca manifestar uma determinada doença, simplesmente por exercerem atividades em ambientes de trabal ho adequados, onde os riscos potenciais de exposição estão controlados (Rawbone, 1999). Outro fator relevante diz respeito à variabilidade genética desses marcadores em diferentes grupos étnicos. Embora importante do ponto de vista evolutivo, essa variabilidade genética pode levar também à segregação ocupacional de minorias étnicas (Soskolne, 1997).

Ainda importante a considerar no screening genético é a confiabilidade dos métodos utilizados para identificar a presença do gene mutado e o risco inerente aos portadores. M es- mo com testes genéticos com especificidade e sensibilidade acima de $90 \%$, deve-se considerar a freqüência da manifestação da doença na população em estudo. A baixa prevalência da doença na população indica que somente uma fração mínima de indivíduos identificados como positivos realmente terá a doença. Assim, aceitando-se os resultados de screening genéticos, todos demais poderão ser, erroneamente, desclassificados para uma determinada função (Van Damme et al., 1995).

As metodologias utilizadas são cada vez mais eficazes para identificar um número crescente de marcadores genéticos em uma única reação, por meio de uma só gota de sangue, que pode ser armazenada e estocada infinitamente em um suporte de papel. A tecnologia dos DNA chips ou microarrays permite a identificação de mais de 1.000 genes em uma única reação e possibilita o screening rápido de um grande número de indivíduos clinicamente saudáveis ( $H$ enn, 1999). Em um futuro bastante próximo, os profissionais de saúde ocupacional deverão estar habilitados para entender e interpretar os resultados provenientes deste tipo de análise para melhor adequar trabalhadores em diferentes funções.

Os ben efícios sociais identificados com a aplicação destes testes ainda são poucos, embora exista uma ten dência em considerar que o uso de resultados provenientes destes testes é parte da responsabilidade da sociedade sobre o futuro relativo à saúde nas coletividades. H oje já se discute o direito que teria a sociedade de impedir, por exemplo, os portadores do gene para doença de $\mathrm{H}$ untington de admissão como pilotos de avião ou maquinistas de trem, situações que poderiam colocar em risco a vida de muitas outras pessoas (Rawbone, 1999).

A coleta de material biológico para qualquer tipo de rastreamento ou teste genético sempre levanta dúvidas quanto à privacidade dos resultados, perigos de sua utilização, e impacto psicossocial desses resultados. Os riscos da análise genética devem ser explicitados, da forma mais clara possível, principalmentelevando-se em consideração que as pesquisas nessa área são incipientes e que a importância e aplicação dos resultados obtidos ainda requerem maior discussão. N esse tipo de pesquisa, embora os resultados obtidos sejam individuais, seu significado faz parte de um contexto global onde grupos ou comunidades são avaliados.

0 mundo do trabalho e das relações tra- 
balhistas é uma das áreas com grande potencial para o uso não ético dos marcadores biológicos moleculares (O menn, 1982; Vineis \& Schulte, 1995). Os testes genéticos podem acarretar "riscos individuais" na sua interpretação eter efeito devastador na capacidade de indivíduos em conseguir ou manter seus empregos, bem como num futuro próximo, em obter seguro saúde. Por essa razão, alguns autores têm sugerido a utilização do termo "análise genética" no lugar de "testes genéticos" com intuito de minimizar os efeitos discriminatórios (H ainaut \& V ähäkangas, 1999). Por outro lado, a ênfase na identificação da variabilidade individual pode levar a uma fal sa sensação de segurança, que privilegiaria a sel eção de certos trabalhadores para determinadas funções e com o possível comprometimento do rigor no controle de condições de segurança do ambiente de trabalho.

Direitos conflitantes sempre levantam questões éticas delicadas como, por exemplo, direito de proteção ao emprego versus direito de proteção à saúde; direito à informação versus direito à privacidade; direito individual versus direito da coletividade. Neste sentido, algumas normas de conduta devem ser asseguradas ao profissional de saúde ocupacional para garantir a execução de suas funções com independência em relação a empregadores e trabalhadores. Deve-se também ressaltar o direito do trabalhador em recusar sua participação desses rastreamentos, uma vez que os resultados poderão vir a configurar algum tipo de segregação subseqüente. Serão necessários programas de esclarecimento envolvendo empregados e empregadores, para que os benefícios oriundos do mapeamento genético sejam utilizados tendo como prioridade absoluta a saúde.

\section{Conclusões}

As ações em saúde do trabalhador têm como objetivo maior proteger a saúde e promover a manutenção de um ambiente saudável e seguro para o trabal hador, bem como adaptar sua capacidade física e psicológica à sua ocupação.

A suscetibilidade individual à exposição a substâncias químicas, por exemplo, pode configurar uma situação de risco importante, principalmente para trabalhadores com baixos níveis de exposição e assim considerados como operando em condições seguras. A pesquisa da presença de marcadores genéticos na população e sua interação com exposições am- bientais sobre o risco de doenças é uma área de estudo relativamente recente. Princípios éticos devem nortear a aplicação de testes genéticos em estudos epidemiológi cos ocupacionais, pois para os cientistas os resultados obtidos podem apenas fazer parte de um grande quebra-cabeça, enquanto para os demais segmentos da sociedade podem ser usados e interpretados de formas diferentes, al gumas certamente equivocadas, com implícitos desdobramentos legais. A estratégia para reduzir os danos causados à saúde do trabal hador deve continuar a ter como base, prioritariamente, a modificação e a adequação dos ambientes de trabalho e não a especificação genética da força de trabalho.

\section{Referências bibliográficas}

Armstrong BK, White E, Saracci R 1992. Principles of exposure measurement in epidemiology. Oxford University Press, 0 xford.

Austin M A, Peyser PA, Khoury MJ 2000. The interface of genetics and public health: research and educational challenges. Annual Review of Public Health 21:81-99.

Bergen AW, Caporaso N 1999. Cigarette smoking. Journal of N ational Cancer Institute 91:1.365-1.375.

Caporaso N, Landi MT, Vineis P 1992. Relevance of metabolic polymorphism to human carcinogenesis: evaluation of epidemiologic evidence. Pharmacogenetics 2:4-19. 
Collins FS 1999. Shattuck Lecture: medical and societal consequences of the H uman Genome Project. N ew England Journal M edicine 341:28-37.

Collins FS, M cKusick VA 2001. Implications of the Human Genome Project for medical science. Journal of the American M edical Association 285:540-544.

Ellsworth DL, M anolio TA 1997. The emerging importance of genetics in epidemiologic research. I. Basic concepts in human genetics and laboratory technology. Annals of Epidemiology 9:1-16.

Gattás GJF, Soares-Vieira JA 2000. Cytochrome P450$2 \mathrm{E} 1$ and glutathione S-transferase mu polymorphisms among Caucasians and mulattoes from Brazil. Occupational M edicine 50:508-511.

Goodman KW, Prineas RJ 1996. Towards and ethics curriculum in epidemiology, pp. 290-303. In SS Coughlin \& TL Beauchamp (eds.). Ethics and Epidemiology. Oxford University Press, N ova York.

H ainaut P, Vähäkangas K 1999. Genetic analysis of metabolic polymorphisms in molecular epidemiological studies: social and ethical implications, pp. 395402. In P Vineis et al. (eds.). M etabolic Polymorphism and Susceptibility to Cancer. (IARC Scientific Publications No 148). IARC Press, Lyon.

Henn W 1999. Genetic screening with the DNA chip: a new pandora's box? Journal M edical Ethics 25:200203.

Holtzman N A, Andrews LB 1997. Ethical and legal issues in genetic epidemiology. Epidemiology Review 19:163-174.

Hulka BS, Griffith JD, Wilcosky TC 1990. Biologic markers in epidemiology. Oxford University Press. N ova York.

IARC 1987. International Agency for Research on Cancer. O verall evaluations of carcinogenicity: an updating of IARC M onographs Volumes 1 to 42. IARC $M$ onographs on the evaluation of the carcinogenic risks to humans. Supplement 7. IARC, Lyon.

IARC 1999a. International Agency for Research on Cancer. Re-evaluation of some organic chemicals, hydrazine and hydrogen peroxide (part one). IARC $M$ onographs on the evaluation of the carcinogenic risks to humans, vol. 71. IARC, Lyon.

IARC 1999b. International Agency for Research on Cancer. Re-evaluation of some organic chemicals, hydrazine and hydrogen peroxide (part two). IARC $M$ onographs on the evaluation of the carcinogenic risks to humans, vol. 71. IARC, Lyon.

IARC 1999c. International Agency for Research on Cancer. Re-evaluation of some organic chemicals, hydrazine and hydrogen peroxide ( part three). IARC $M$ onographs on the evaluation of the carcinogenic risks to humans, vol 71. IARC, Lyon.

Khoury M J, Beaty TH, Cohen BH 1993. Fundamentals of genetic epidemiology. Oxford U niversity Press, N ova York.

Khoury MJ 1998. Genetic epidemiology, pp. 609-621. In KJ Rothman, S Greenland. M odern epidemiology (2a ed.). Lippincott, Williams and Wilkins, Filadélfia.

O menn GS 1982. Predictive identification of hypersusceptible individuals. Journal $O$ ccupational M edicine 24:369-374.

Parkinson A 1996. Biotransformation of xenobiotics, pp.113-86. In Klassen CD (ed.). Casarett \& Doull's Toxicology: The basic science of poisons. M CGrawHill, N ova York.

Perera FP et al. 1990. M olecular epidemiology and cancer prevention. Cancer Detection and Prevention
14:639-45.

Perera FP, Dickey C 1997. M olecular epidemiology and occupational health. Annals $\mathrm{N}$ ew York A cademy of Sciences 837:353-359.

Peto 2001 . Cancer epidemiology in the last century and the next decade. $N$ ature $411: 390-395$

Plotsky PM , N emeroff CB 1998. M olecular mechanisms and regulating behavior. pp. 979-988. In Principles of M olecular M edicine. Jameson JL (ed.). H umana Press, Totowa, Nova Jersey.

Rothenberg K et al. 1997. Genetic information and the workplace: legislative approaches and policy challenges. Science 275:1.755-1.757.

Raunio $\mathrm{H}$ et al. 1995. Diagnosis of polymorphisms in carcinogen-activating and inactivating enzymes and cancer susceptibility: a review. Gene 159:113-121.

Rawbone RG 1999. Future impact of genetic screening in occupational and environmental medicine. 0 ccupational Environmental H ealth 56:721-724.

Schulte PA, Perera FP 1993. M ol ecular epidemiology: principles and pratices. Academic Press, N ova York.

Smith G, Stanley LA, Sim E, Strange RC, W olf CR 1995. $M$ etabolic polymorphism and cancer susceptibility. Cancer Survey 25:27-65.

Soskolne CL 1997. Ethical, social, and legal issues surrounding studies of susceptible populations and individuals. Environmental $\mathrm{H}$ ealth Perspectives 105: 837-841.

Taningher M, M alacarne D, Izzoti A, U golini D, Parodi $S$ 1999. Drug metabolism polymorphism as modulators of cancer susceptibility. M utation Research 436:227-261.

Vainio H, Sorsa M, M cM ichael AJ 1990. Complex mixtures and cancer risk. (IARC Scientific Publication № 104). I ARC, Lyon.

Van Damme K et al. 1995. Individual susceptibility and prevention of occupational diseases: scientific and ethical issues. Journal 0 ccupational and Environmental M edicine 37:91-99.

Venter JC et al. 2001. The sequence of the Human Genome. Science 291:1.304-1.351.

Vermeulen R 2001. Genotoxic exposure and biologic effects in the rubber manufacturing industry. Relevance of the dermal route. Doctoral Thesis. Utrecht University, U trecht.

Vineis P, Schulte PA 1995. Scientific and ethical aspects of genetic screening of workers for cancer risk: the case of $\mathrm{N}$-acetyltransferase phenotype. Journal Clinical Epidemiology 48:89-197.

Wicks AC, Sever LE, H arty R, Gajewski SW, M arcusSmith M 1999. Screening workers for genetic hypersusceptibility: potential ethical, legal, and social implications from the Human Genome Project. Journal of $\mathrm{H}$ ealth and $\mathrm{H}$ uman Service Administration 22:116-132.

Wünsch Filho V, Gattás GJF 2001. Biomarcadores moleculares em câncer. Cadernos de Saúde Pública 17: 467-480.

Wünsch Filho V 2000. Interação dos efeitos de consumo de tabaco e câncer na família no risco de câncer de pulmão. Tese de Livre-D ocência. Faculdade de Saúde Pública, U niversidade de São Paulo, São Paulo. 